\title{
Flipped Classroom and Its Application to College English Teaching
}

\author{
Hongtao Yin \\ College English Department, Zaozhuang University \\ Zaozhuang, Shandong Province, China
}

\begin{abstract}
Flipped classroom is a brand-new form of classroom teaching. The thesis analyzes the feasibility of flipped classroom instructing college English teaching and probes into its teaching process. In spite of the advantages of flipped classroom, it is a big challenge to the teachers as well as students.
\end{abstract}

Keywords—flipped classroom; feasibility; teaching process

\section{INTRODUCTION}

With the rapid development of information technology, educational informationization emerges against the background of global informationization, giving rise to new educational ideas, models and trends. Just as informationization and big data have changed the mode of transmission of information, people's work, life and ways of communication, and commercial modes, educational informationization also allows possibilities of receiving education, like online virtual classroom, MOOC, and Flipped classroom, which have come to be well-known in close relevance with educational informationization.

Flipped classroom, a brand-new form of classroom teaching, was initiated by Woodland Park High School chemistry teachers Jonathan Bergmann and Aaron Sams, who recorded their lectures and posted them online, drawing great public attention. In 2011, Salman Khan and his Khan Academy became driving forces in flipped teaching. From then on, Flipped classroom came to be known among teachers, its teaching ideas and methods gradually being accepted. Moreover, it was rated by The Globe and Mail as one of the major technological changes of 2011 that would influence classroom teaching. In addition, world famous universities offered online representative teaching and learning resources, including MIT Opencourseware Movement, open classes of Yale, TED educational channel, etc. which, as the high-quality teaching materials, have promoted the development of Flipped classroom.

Flipped classroom, a new model of teaching, is characterized by students' watching online lectures before classes, working on the assignments, and collaborating in classroom discussions with the guidance of a teacher.(Zhong, 2013 ) Other scholars argue that the key to the flipped

The thesis is a phrasal achievement of "A Case Study on the Application of Flipped Classroom to College English Listening and Speaking Classroom", a Special Subject for Foreign Language of Higher Education, Shandong Provincial Project of Education Science. The number of the project is CBW15013. classroom is not the teaching videos but the students-oriented thinking, a subversion of the traditional teaching procedures. The success of the flipped classroom lies in the students' inquiry-based and project-based learning with active involvement. (Jin, 2012)

\section{FEASIBILITY OF THE FLIPPED CLASSROOM INSTRUCTING COLLEGE ENGLISH TEACHING}

\section{A. Plight of College English Teaching}

Currently, compared with the English teaching in high schools, college English teaching, although having been released from the bondage of promotion, is still examinationoriented, including CET4/6, TOEFL, IELTS and the English examination for master degree, which needs reforming badly. English language leaning serves for the learning of culture, and should pay more attention to the cultivation of communicative skills in listening and speaking, which is based on the good command and flexible application of foundation knowledge of English vocabulary, grammar, reading comprehension and writing, which can be achieved only in good language environment.

Due to the restrictions in limited teaching time, space and content, college English teaching fails to be carried out in a perfect teaching environment. As a consequence, it will be hard to train and improve the non-English major students' five basic skills, i.e. listening, speaking, reading, writing and translation in an all-round way. In the 45-minute class, the teacher needs to pass on the knowledge in the textbook to the students who, correspondingly, are busy listening and taking notes with concentration, and have few opportunities to speak in English. Even they have, they are so nervous, sacred, timid and shy that they dare speak out. As a result, the teacher fails to offer timely relevant instructions in pronunciation correction, listening and speaking, etc. Some English classes are characteristic of rigid content, boring design, and stereotyped teaching model. The students in the English classroom can only learn well but fail to apply. Over time, in their hearts appear resistance due to fatigue, boredom and dullness. Without comprehensive study mastery cannot be achieved, which will have strong impact on the effect of college English teaching.

\section{B. Advantage of Flipped Classrooms in the College English} Teaching

1) New teaching model featuring "learning before teaching" contributes to the cultivation of students' independent learning ability. According to Eric Mazur, the 
learning process primarily includes knowledge transmission and knowledge internalization. In the traditional model of classroom instruction, the teacher disseminates knowledge firstly and then after class students internalize the knowledge by finishing the assignments given by the teacher. Once students run into questions in the process of internalization while the teacher is not available for timely help, the effect of internalization is influenced. The essence of Flipped classroom is the reversion of knowledge transmission and knowledge internalization, the former shifting from in-class to after-class or home while the latter shifting from after-class or home to in-class. Thus, the process is wholly reversed in time and space, a new teaching model of "learning before teaching". In addition, in the process of internalization, the teacher's company and involvement do help to solve students' problems timely and effectively. In the process of cooperation and discussion with peers, students succeeded in the digestion, consolidation and comprehensive mastery of knowledge, which will maximize the role of the key link --internalization. Thus, both the teaching effect and the learning effect are all greatly improved, which is exactly the greatest advantage of Flipped classroom over the traditional classrooms.

In the mode of Flipped classroom, the college English teacher needs to concentrate the teaching points into micro videos of 15-20 minutes in which the teacher will not show up, avoiding the distraction caused to the students by the outside factors like the teachers' dress. The teacher can infuse animation, stories, funny quiz and other elements into the production of micro videos, releasing the students from the boring learning of textbooks, and arousing their interest in learning college English with the combination of a lot of fun. The concentration of micro videos helps eliminate the disadvantage of distraction caused in the 45-minute class. The students watch the videos with concentration after class or at home and then finish the online exercises to check the learning effect. Meanwhile, they can determine whether to play back, halt or repeat according to their digestion of new knowledge, which, equivalent to the process of transmission initiated by the teacher in the traditional classrooms, overcomes the drawback of unidirectionality of knowledge transmission in the traditional classrooms, shortening the time of knowledge transmission.

It should be noted that the quality of in-class teaching is based on the students' independent and effective learning. Only after the students absorb the knowledge by means of self-study can they achieve the high-quality of internalization of the knowledge, turning the knowledge into the ability of application. They gradually get rid of the psychology of relying on teachers, independently explore new knowledge and expect from their heart the skillful expression and communication with the knowledge they have acquired. Farewell to "dumb" English. Therefore, the reversed transmission of pressure inside the flipped classrooms prompts the students to improve their ability of self-study, which will benefit the students in all their life. As the famous saying goes, "teaching one to fish is better than giving him fish". It's in accordance with the educational informationization and the educational concept of lifelong learning.
2) Flipped classroom realizes effectively the function of classrooms and helps improve the reversion and promotion of the roles of student and teacher. The traditional teaching mode focuses on the maximization of knowledge transmission conducted in the classroom in a fixed period of time and limited space, i.e. how to optimize the transmission of teaching content and the arrangement of teaching procedure. While stressing the maximization of knowledge transmission in the teaching activity, this mode neglects the true subject in the learning process, the individuality of students' original level and the differentiation of receptive ability, failing to conduct differentiated hierarchized teaching. As a consequence, the function of classroom is badly brought into play and the teaching effect not so satisfactory. However, Flipped classroom, a mode featuring the combination of online learning and differentiated instructions, contributes to the students' digestion and internalization of knowledge to the greatest extent and gives full play to the students' principal role in the learning process, realizing effectively the students individualized differentiated development. Moreover, the function of classrooms is brought to play and upgraded practically and effectively, making up the inadequate play in the traditional teaching mode and achieving the value appeal for the highly effective classrooms.

What is worth mentioning is that Flipped classroom is not a synonym for video teaching. The core and key of a flipped classroom lie in the internalization of knowledge manifested by the interactions and communications between teachers and students. On the surface, it seems that Flipped classroom replaces the teachers with video teaching and correspondingly the teachers' role is weakened. However, in essence, there appears a double change, i.e. the teachers' role changes from "the saint on the platform" to "the instructor beside the students" while the students' role from "a passive acceptor of knowledge" to "an active explorer of knowledge", which means the true return to its origin of "master of learning". The teachers become the "mentor" of students in the process of internalization, which strengthens rather than weakens their role. Due to the subjective and objective limitations, currently the cultivation mechanism for the non-English majors' listening and speaking is not adequately perfected. It is no longer the case in the Flipped classroom where on the premise of guaranteeing the realization of the transmission of knowledge from textbooks, the teacher communicates with the students in English centering on Q\&A, helping them with the internalization of knowledge and the correction of pronunciation and expression, and meanwhile, the time and space of the students' expressing in English are prolonged and expanded respectively, making sure that a large amount of language output is realized on the premise of a large amount of language input, which helps the students have self-confidence in deepened self-study with the senses of self-fulfillment and self-accomplishment.

3) Flipped classroom sets up the diversified mechanism for interactions, contributing to the cultivation of the new teacherstudent model. In the traditional teaching mode, the teacher, the primary operator of knowledge transmission, has always the absolute right of speech. In the teacher-oriented mode the teacher takes the dominant position while the students the secondary position in the teacher-student relationship that 
should have been fair originally. As a consequence, the students' ideology and thinking on bold innovation, brave query and argument are greatly restrained and fettered. In contrast, in Flipped classroom, the one-way teacher-student class activities change into bilateral interactions between teachers and students featuring the diversified teacher-student and student-student communication mechanism. In this multidimensional mechanism, the interactions and emotion communications between teachers and students are increased, the teacher can help the students with the ability of internalization of knowledge, the students' comprehensive quality featuring creative thinking, divergent thinking and logical thinking with the combination of the abilities including independent exploration, argument, communication, problemsolving, collaborative cooperation, are effectively cultivated, thereby enhancing the learning effect.

In addition, this teaching mode eliminates the hierarchy between the teacher and the students, accelerating the equalization between teaching and learning and contributing to the reshaping of teacher-student relationship. In the interactive communications, the students obtain good emotional experience. In their mind, the teacher no longer retains supremacy but becomes the mentor in learning and the friend in life. This growing friendship between teachers and students can turn into the spiritual impetus for the students to overcome setbacks, reduce the students' fears and lack of confidence. The students can obtain double support and encouragement in psychology and spirit in the face of bewilderment and confusion, contributing to the cultivation of resistance against stress and setbacks, and the spirit of exploration. A virtuous cycle of teaching and learning benefiting each other, the best relation between teaching and learning, is eventually formed.

4) Flipped classroom contributes to the realization of educational equality and the re-integration and optimization of educational resources. The maldistribution of educational resources and the difference in educational quality are common in every country or region of the world. Flipped classroom, the product of the information age beyond the boundaries of countries, reflects the true social appeal for knowledge and fair competition, which has aroused vast strong resonance in the circle of education. Via the micro-lectures produced, the teacher can integrate high-quality college English teaching resources of different countries or regions and infuse them into the micro-lectures for students' self-study, which can make up and smooth out the regional differentiation in education, letting the college students of various levels have access to topquality educational resources of elite universities. This kind of undifferentiated knowledge transmission effectively makes up for the regret in English teaching caused by the individualized difference in knowledge reserve and teaching methods and levels, overcomes the blockage or invalidation of knowledge transmission and also breaks to some extent the monopoly of high quality educational resources which is thereby accessible to every student in different countries or regions. Compared with the traditional teaching role, Flipped classroom plays an unmatched role in the reintegration and optimized allocation of educational resources, truly realizing the educational fairness.

\section{Teaching Process In FLIPPED ClassRoOM}

\section{A. Pre-class}

In a traditional English classroom, the teacher usually assigns preview work for the learners, including looking new words up, reading to roughly understand the text, etc. A flipped classroom requires the teacher not only to play his/her dominant role to guide the students to carry out teaching activities smoothly, but also mobilize their subjectivity to construct knowledge actively. The teaching links are mainly as follows.

Preparation of the teaching videos and presentation of exercises. The teaching videos include not only high-quality online teaching resources but also the micro-lectures produced for teaching. Firstly, there are many top quality teaching video resources, home and abroad, on the Internet, like TED introduced by NetEase, curricula byKhan Academy, open courses by international elite universities, Coursera, open video courses by Chinese universities, etc. covering the content in English in fields like literature, history, language, education, etc. in addition, there are also many high-quality video resources in foreign languages on Youku, Sohu, Tencent and other video websites with downloading and transcoding available. Secondly, the foreign language teachers themselves can also produce, according to the content, objectives and the degree of the students' understanding, the micro-lectures which are more suitable for the learners' learning than the ones downloaded directly from the Internet. It' $\mathrm{s}$ noted that a micro-lecture should not be too long, usually within ten minutes, for a learner' $s$ attention is usually maintained for 5-8 minutes. If the teacher makes the micro-lectures themselves, the lectures should highlight the interactivity, theme and a whole teaching link with full display of a certain knowledge point.

Meanwhile, the foreign language teacher should finish preparing not only the micro-lectures but also a certain amount of exercises which can stimulate the learners' thinking about the teaching content, arouse their learning interest, and help them check the learning effect and discover the difficult and key points. The amount of the exercises should not be too large in case of too much pressure to be brought to the students.

Students' independent study and pre-class exercises. The learners watch online lectures according to their own situations. They can choose to play back or watch repeatedly for the difficulty or key points, or fast-forward for the familiar points. Thus, the learners of different levels can adjust their learning by themselves. Moreover, they can be more relaxed in the selfstudy environment than in the classrooms, cultivate their ability to solve problems by surfing the Internet or referring to books, and consolidate their learning of the content by finishing the assigned exercises. They can also communicate with their teachers and classmates in the classrooms or after class when running into questions that they cannot solve.

The pre-class interactions between the teacher and students, and between students. Students are bound to come across certain problems in their learning before class. Students can choose to communicate with each other and with teachers via 
diversified social media, for example, message board in the online classes, chatting rooms, QQ, WeChat, telephones, etc.

\section{B. In-class}

In the flipped classrooms of foreign languages, the teacher can, by introducing the key and difficult points in advance, help students acquire and eventually internalize the knowledge.

1) Question \&answer/ discussion.The foreign language teacher can guide the students to discuss and answer the questions concerning the difficult and key points generated in the pre-class learning, which places high demands on the foreign language teachers, requiring them not only to steer the discussion in case of divergence but also to possess the solid mastery of major knowledge, keen strain capacity and language organizing ability.

2) In-class activities.In view of the learners' having learned the teaching content independently, the teacher doesn't need to repeat the knowledge they have acquired, but rather organize various teaching activities, for example, group exploration, contest, discussion, achievement exhibition, speech, etc., which not only promote their interest and participation, but also deepen their understanding of knowledge, thereby developing their team spirit, collaboration ability, innovative thinking and communicative skills.

\section{After-class}

1) Reflection. After class the teacher can assign more tasks to help students further consolidate the internalization of knowledge and meanwhile reflect on their learning result to judge whether they have mastered the teaching content so as to move on to the next stage of learning, or go on remedying the neglected and difficult points. The teacher can also judge the effectiveness of the teaching, the degree of the students' acceptance and the finishing of the teaching content in light of the students' performance.

2) Teaching evaluation. The teaching evaluation can take the form of activity record, interview, questionnaire, teaching journal, test, etc. concerning the allotment of time, performance, learning plan, acceptance, satisfaction, emotion, motive, independent solution, etc. Through the teaching evaluation, the foreign language teacher can improve the teaching in the flipped classrooms, promote the teachers' quality of teaching, adjust the teaching strategy and make the new teaching plans.

\section{Challenges FaCed by FlipPed ClassRoom of FOREIGN LANGUAGES}

\section{A. Challenge from the Modernized IT}

The knowledge of computer hardware and software like PPT, computer screen recording, video clipping and transcoding, network platform operating, etc. does great help to the success of Flipped classroom of foreign languages. On one hand, the school should provide relevant facilities and technical support for teachers and students. On the other hand, the teacher should possess the corresponding qualities, for example, how to record the Flipped classroom, communicate with students on the online forum, operate the online teaching platform, etc.

\section{B. Challenge on the Teacher's Teaching Ability}

In the traditional classroom, it's enough for a teacher to make a success out of every class. However, in the flipped classroom, the teacher needs not only to do well in every class, but also prepare the micro-lectures in advance, organize the learners to carry out various activities, help them to explore questions and have good and timely communications with them, more importantly, to motivate them, pay attention to their emotions, and take into account individual differences and demands, which places higher demands on the teacher' teaching ability.

\section{Challenge on the Teaching Evaluation}

In the past the evaluation of curricula was usually manifested in the students' grades or simple questionnaire. However, the flipped classroom of foreign languages involves many other teaching factors, for example, learners' allotment of learning time, personal emotion, learning motive, exchanges and collaboration, group activities, learning attitude, learninginfluencing factors, etc. All these factors will have impact on the transformation of teaching evaluation and the diversification of forms of evaluation, which include, in addition to the traditional tests and questionnaire, online surveys, interviews, records of activities, teaching journals, etc.

\section{Challenge on Adaptiveness}

In view of our national conditions, the adaptiveness of Flipped classroom should be taken into consideration from the perspective of school, teacher and student. In terms of school, Flipped classroom needs the support of multimedia hardware and software, 'which requires the school to have adequate financial and human resources to provide comprehensive service. Moreover, the school should have enough teaching resources and qualified teachers to carry out the teaching in Flipped classroom which is characterized by small-class teaching. What' s more, Flipped classroom should focus on the students' development of test skills so as to guarantee higher enrollment rate. In terms of teacher, the teachers should prepare themselves well in psychology, quality and time for Flipped classroom. In terms of student, the students should shift from the traditional teacher-dominated classroom to the teaching environment in Flipped classroom by participating in more class activities and learning independently.

\section{CONCLUSION}

Flipped classroom does not necessarily take advantage of modernized IT. Instead, IT enables Flipped classroom to have more abundant teaching resources, flexible forms and diversified media, which helps students blend in the teaching activities. Compared with traditional and online classrooms, Flipped classroom attaches more importance to the interactivity and autonomy of learning. Furthermore, with the abundant online resources, the teachers are able to select the most suitable ones to enrich their teaching, making the demonstration of knowledge more vivid. By communicating equally with the learners, the teachers can help them accept and explore knowledge in terms of emotion and perception, and cultivate their innovation and critical thinking. 
To sum up, due to the problems like the reform of national entrance examination, the employment pressure of foreign language graduates', the separation between foreign language teaching and real life, etc., the reform of foreign language teaching is imperative. From the perspective of foreign language learners, Flipped classroom reverses the traditional learning environment and aims at forming a new feasible teaching model featuring the relocation of the roles of teachers' and students', the combination of modernized IT and classrooms and the internalization of knowledge through the students' autonomous learning and communications with teachers.

\section{REFERENCES}

[1] Clark, R. Reconsidering Researching on Learning from Media[J].Review of Education Research. 1983, 53(4):445 459.

[2] Gerald C. Cannod, Janet E. Burge, Michael T. Helmick. Using the Inverted Classroom to teach Software Engineering[A]. 2008 ACM/IEEE $30^{\text {th }}$ International Conference on Software Engineering, 2008:777-786

[3] Jeremy F. Strayer. How learning in an inverted classroom influences cooperation, innovation and task orientation [J].Learning Environ Res , 2012, (15):171-193

[4] Justin G. Gardner. The Inverted Agricultural Economics Classroom: A new way to teach? A new way to learn? [A] .presentation at the Agricultural \& Applied Economics Association's 2012 AAEA Annual Meeting, Seattle[C]. Washington, 2012:12-14.

[5] Resnick, L.(1987).Education and Learning to Think[M].Washington, D.C.: National Academy Press.

[6] Strayer, J. The Effects of the Classroom Flip on the Learning Environment: A Comparison of Learning Activity in A Traditional Classroom and Flip Classroom that Used An Intelligent Tutoring System [D].OH:The Ohio State University, 2007. 